\title{
The Relationship Between Timing of Surgery and Operative Complications in Aneurysmal Subarachnoid Hemorrhage
}

\author{
William S. Tucker
}

\begin{abstract}
The optimal timing of definitive aneurysm repair following subarachnoid hemorrhage remains a controversial issue. In order to examine whether the timing of surgery alters the incidence of certain technical difficulties and complications associated with intracranial aneurysm repair, data from two recent co-operative studies were examined. The cases submitted to the International Co-operative Study on Timing of Aneurysm Surgery by the University of Toronto hospitals, and the cases submitted from multiple centres to the Three-Dose Multicentre Randomized Double-Blind Nimodipine Study were evaluated with regard to operative difficulties and complications, comparing early ( $\leqslant 3$ days) and late ( $\geqslant 4$ days) surgery following subarachnoid hemorrhage. No significant differences were found in the incidence of such technical problems between the early and late surgical groups. If differences in outcome occur between comparable groups of patients operated early and late after aneurysm rupture, factors other than surgical technical complications may be responsible.
\end{abstract}

RÉSUMÉ: Relation entre le moment choisi pour l'intervention chirurgicale et les complications opératoires dans I'hémorragie sous-arachnoidienne due à un anévrisme Le choix du moment optimal pour la réparation définitive d'un anévrisme à la suite d'une hémorragie sous-arachnoïdienne demeure un sujet controversé. Nous avons examiné les résultats de deux études coopératives récentes dans le but de vérifier si le moment choisi pour procéder à l'intervention chirurgicale modifie l'incidence de certaines difficultés techniques et des complications associées à la réparation des anévrismes intracrâniens. Les cas soumis à l' International Co-operative Study on Timing of Aneurysm Surgery" par les hôpitaux affiliés à l'Université de Toronto et les cas soumis par plusieurs centres au "Three-Dose Multicentre Randomized Double-Blind Nimodipine Study" ont été évaluées en ce qui a trait aux difficultés et complications opératoires, en comparant la chirurgie précoce $(\leqslant 3$ jours) et tardive ( $\geqslant 4$ jours) après une hémorragie sousarachnoïdienne. Nous n'avons décelé aucune différence significative dans l'incidence de ces problèmes techniques entre les groupes à chirurgie précoce et tardive. S'il existe des différences dans les résultats entre des groups de patients comparables ayant été opérés précocement et tardivement après la rupture de l'anévrisme, des facteurs autres que les complications découlant de la technique chirurgicale utilisée peuvent en être reponsables.

Can. J. Neurol. Sci. 1987; 14:84-87

The optimal time for surgical repair of an intracranial aneurysm following spontaneous subarachnoid hemorrhage (SAH) remains controversial. ${ }^{1-6}$ Concerns have been raised that there may be increased technical difficulties at operation in patients submitted to craniotomy for aneurysm repair soon after $\mathrm{SAH}$ (Early Surgery) as opposed to those whose aneurysm repair is delayed (Late Surgery). ${ }^{5.7 .8}$

To examine this issue, data have been extracted from two prospective studies of aneurysmal SAH. The material includes all the cases submitted by the University of Toronto hospitals to the International Co-operative Study on Timing of Aneurysm Surgery, as well as all cases submitted by Canadian centres (University of Toronto and University of Alberta) and U.S. centres to the Three-Dose Multicentre Randomized DoubleBlind Nimodipine Study.

\section{Material}

1. The International Co-operative Study on Timing of Aneurysm Surgery:

From January 1981 until June 1983, the University of Toronto hospitals entered 240 valid cases to the International Co-operative Study on Timing of Aneurysm Surgery. One hundred and ninetythree of these patients underwent craniotomy for repair of a ruptured cerebral aneurysm. Forty-nine of these patients underwent early operation (0-3 days post-SAH); 144 patients underwent intracranial aneurysm repair 4 or more days following SAH (Late Surgery).

The decision as to the timing of aneurysm surgery following the SAH was made by the individual attending surgeon for each patient, and was not assigned in any randomized fashion. 
However, comparison of the characteristics for the early and late groups suggests that the two groups were quite similar with regard to a number of characteristics thought to be relevant to prognosis.

The mean age of the early group was 50.8 years, and the mean age of the late group was 47.2 years. The average blood pressure on admission for the early cases was $146.7 \mathrm{~mm} \mathrm{Hg}$ systolic and $86.2 \mathrm{~mm} \mathrm{Hg}$ diastolic; the average blood pressure for the late cases was $146.2 \mathrm{~mm} \mathrm{Hg}$ systolic and $85.9 \mathrm{~mm} \mathrm{Hg}$ diastolic.

The neurological status of the patients in the early and late groups was comparable at presentation (Table 1). No significant differences were found between the two groups in level of consciousness, orientation and appropriateness of response to command at presentation.

Table 2 shows the characteristics of the initial CT scans, which were fairly similar for the two groups of patients.

Table 3 lists the characteristics of the aneurysms demonstrated by angiography in the two groups. The difference in the incidence of middle cerebral artery aneurysm between the early $(25 \%)$ and late $(11.1 \%)$ groups does reach significance $(p<$ 0.05 ), but there was no significant difference in frequency of occurrence of aneurysms in the other sites, or in the various sizes of aneurysm.

The data collection for the International Co-operative Study on Timing of Aneurysm Surgery permitted assessment of the incidence of a number of operative difficulties and complications in the early and late groups of patients. Data were available for intra-operative bleeding from the aneurysm, the occurrence of a "tight brain" despite measures to reduce

Table 1: Neurological Characteristics at Presentation: University of Toronto Cases in the International Co-operative Study on Timing of Aneurysm Surgery

\begin{tabular}{lcc}
\hline \hline & $\begin{array}{c}\text { Early Group } \\
(\mathbf{N}=49)\end{array}$ & $\begin{array}{c}\text { Late Group } \\
(\mathbf{N}=144)\end{array}$ \\
\hline $\begin{array}{l}\text { Level of Consciousness } \\
\text { Fully Alert }\end{array}$ & $27(55.1 \%)$ & $78(54.2 \%)$ \\
$\begin{array}{l}\text { Drowsy } \\
\text { Stuporous }\end{array}$ & $18(36.7 \%)$ & $40(27.8 \%)$ \\
Comatose & $3(6.1 \%)$ & $14(9.7 \%)$ \\
Orientation & $1(2.0 \%)$ & $12(8.3 \%)$ \\
Normal & & \\
Impaired & $33(67.3 \%)$ & $95(66.0 \%)$ \\
Response to Commands & $16(33.7 \%)$ & $49(34 \%)$ \\
Appropriate & & \multicolumn{2}{c}{} \\
Inappropriate or None & $39(79.6 \%)$ & $108(75 \%)$ \\
\hline
\end{tabular}

Table 2: CT Scan Characteristics at Presentation: University of Toronto Cases in the International Co-operative Study on Timing of Aneurysm Surgery

\begin{tabular}{lcc}
\hline \hline & $\begin{array}{c}\text { Early Group } \\
(\mathbf{N}=\mathbf{4 9 )}\end{array}$ & $\begin{array}{c}\text { Late Group } \\
(\mathbf{N}=144)\end{array}$ \\
\hline $\begin{array}{l}\text { SAH on CT } \\
\text { Diffuse Deposition }\end{array}$ & $19(38.8 \%)$ & $44(30.6 \%)$ \\
Localized Thin Layer & $10(20.4 \%)$ & $42(29.2 \%)$ \\
Localized Thick Layer & $7(14.3 \%)$ & $32(22.2 \%)$ \\
No SAH Seen & $13(26.5 \%)$ & $26(18.1 \%)$ \\
Hydrocephalus & $8(16.3 \%)$ & $27(18.8 \%)$ \\
Intraventricular & $11(22.4 \%)$ & $27(18.8 \%)$ \\
Hemorrhage & & \\
Intracerebral & $7(14.3 \%)$ & $15(10.4 \%)$ \\
Hemorrhage & &
\end{tabular}

Table 3: Aneurysm Characteristics in the Early and Late Groups of the University of Toronto Cases in the International Co-operative Study on Timing of Aneurysm Surgery

\begin{tabular}{lcc}
\hline \hline & $\begin{array}{c}\text { Early Group } \\
(\mathbf{N}=49)\end{array}$ & $\begin{array}{c}\text { Late Group } \\
(\mathbf{N}=144)\end{array}$ \\
\hline $\begin{array}{l}\text { Site } \\
\text { Anterior Cerebral Artery }\end{array}$ & $20(41.7 \%)$ & $58(40.3 \%)$ \\
Internal Carotid Artery & $13(27.1 \%)$ & $57(39.6 \%)$ \\
Middle Cerebral Artery & $12(25 \%)$ & $16(11.1 \%)$ \\
Posterior Circulation & $3(6.3 \%)$ & $12(8.4 \%)$ \\
Size & $38(77.6 \%)$ & $108(75.5 \%)$ \\
Small $(\leqslant 12 \mathrm{~mm})$ & $10(20.4 \%)$ & $33(23.2 \%)$ \\
Large $(13-24 \mathrm{~mm})$ & $1(2.0 \%)$ & $2(1.4 \%)$ \\
Giant $(\geqslant 25 \mathrm{~mm})$ &
\end{tabular}

intracranial pressure, the need for major brain resection at operation, the permanent occlusion of perforating or feeding arteries, the ease of dissection of the aneurysm and a miscellaneous group of other complications. It was also possible to compare the six month outcome in the early and late groups, as determined by an independent neurologist.

\section{The Three-Dose Multicentre Randomized Double-Blind Nimodipine Study:}

The three-dose multicentre randomized double-blind nimodipine study also provided an opportunity to compare patients operated on in the early and late intervals or following SAH. The patients in this study were all in good neurological condition at study entry, within 96 hours of a SAH. An entry requirement was that patients had to be neurologically normal apart from headache and meningeal irritation. Isolated cranial nerve palsy or mild drowsiness with preserved orientation at least to person, city and year were permitted. All patients received nimodipine by the oral route, in a dose of $30 \mathrm{mg}, 60 \mathrm{mg}$ or $90 \mathrm{mg}$, every 4 hours. The dose was determined in a randomized fashion. The timing of intracranial aneurysm repair was again decided by the individual attending surgeon for each patient, but the study protocol required that surgery be done within 14 days of study entry, unless a neurological deficit or medical problem developed which made surgery inadvisable.

Throughout North America, 214 patients were enrolled in this study, 203 of whom were operated upon. Only 169 of these 203 patients were compliant with the protocol with regard to the administration of nimodipine. However, all 203 of the patients who underwent operations were analyzed in the present survey. Technical complications and difficulties at operation, comparing early and late surgical groups, were considered. Because the clinical status at entry into the study was determined by the protocol which demanded a good neurological grade, the details of the status at presentation will not be enumerated. Of the 203 patients in the study who underwent operation, 148 cases came from 21 U.S. centres, and 55 came from two Canadian centres. Thirty-three of these cases came from the University of Toronto, and 22 from the University of Alberta. There was a significant difference in the timing of surgery between the U.S. and Canadian groups, the mean day of surgery being 4.77 days from SAH for the U.S. group, and 1.54 days for the Canadian group. This difference is highly significant $(P<0.0005)$, the Canadian centres operating earlier than the U.S. centres (Table 4).

Patients in this study were also divided into an early group (0-3 days post-SAH) and a late group ( $\geqslant 4$ days post-SAH). Fifty-one of the 55 Canadian cases were in the early surgical 
Table 4: Comparison Between Timing of Surgery in Canadian and U.S. Patients in the Three-Dose Multicentre Randomized Double-Blind Nimodipine Study

\begin{tabular}{lcc}
\hline \hline & $\begin{array}{c}\text { Canadian Group } \\
(\mathbf{N}=\mathbf{5 5})\end{array}$ & $\begin{array}{c}\text { U.S. Group } \\
(\mathbf{N}=\mathbf{1 4 8})\end{array}$ \\
\hline Mean Day of Surgery & & \\
Mean Day & 1.54 & 4.77 \\
Standard Deviation & 1.33 & 5.1 \\
Standard Error & 1.12 & 2.3 \\
Range & $0-7$ & $0-22$ \\
Mean Hour of Surgery & & \\
Mean Hour & 49.6 & 129.3 \\
Standard Deviation & 30.7 & 124.4 \\
Standard Error & 5.5 & 11.2 \\
Range & $7.0-188$ & $9.5-559$ \\
\hline
\end{tabular}

group, while the U.S. cases were more evenly divided, with 87 patients receiving early surgery and 61 cases receiving late surgery. The Three-Dose Multicentre Randomized DoubleBlind Nimodipine Study permitted analysis of certain technical complications at surgery, and these were compared between the early and late groups. Operative complications recorded included intra-operative rupture of the aneurysm and permanent clipping of feeding or perforating arteries.

\section{RESULTS}

\section{The International Co-operative Study on Timing of} Aneurysm Surgery:

In the International Co-operative Study on Timing of Aneurysm Surgery there was no significant difference in the incidence of intra-operative bleeding from the aneurysm between the early and late groups (Table 5).

The operating surgeons described the brain as being tight in $26.5 \%$ of the early cases and in $27.1 \%$ of the late cases, despite the use of measures to reduce intracranial pressure intraoperatively. Resection of brain tissue was required in none of the early cases but in 6 of the late cases $(4.2 \%)$. Neither of these two differences is significant. Permanent occlusion of perforating or feeding arteries was reported in one early case $(2.0 \%)$ and 4 late cases $(2.7 \%)$. This difference is not significant. Postoperative arteriograms were not required in this study.

There was no significant difference in the ease of dissection of the aneurysm described for the early and late groups. Dissection was said to be easy in $64.4 \%$ of the early cases, and in $64.0 \%$ of the late cases.

There was no significant difference between the two groups with regard to other complications recorded: major vein occlusion occurred in none of the early or late cases; brain contusion occurred in none of the early cases and in only one of the late cases; brain laceration occurred in one of the early cases and none of the late cases.

Table 6 lists the status of the patients 6 months after SAH in all patients who were still alive at 6 months. The differences do not reach statistical significance.

\section{The Three-Dose Multicentre Randomized Double-Blind} Nimodipine Study:

In the Three-Dose Multicentre Randomized Double-Blind Nimodipine Study the incidence of technical difficulties and complications at operation were compared between the early and late groups, and also between the Canadian group, which
Table 5: Intra-operative Aneurysm Rupture in the Early and Late Surgical Groups of the University of Toronto Cases in the International Co-operative Study on Timing of Aneurysm Surgery

\begin{tabular}{lcr}
\hline \hline & $\begin{array}{c}\text { Early Group } \\
(\mathbf{N}=\mathbf{4 9})\end{array}$ & $\begin{array}{r}\text { Late Group } \\
(\mathbf{N}=144)\end{array}$ \\
\hline Rupture & $8(16.3 \%)$ & $18(12.5 \%)$ \\
Leak & $3(6.1 \%)$ & $7(4.9 \%)$ \\
Hemorrhagic Shock & $0 \quad(0 \%)$ & $0 \quad(0 \%)$ \\
\hline
\end{tabular}

Table 6: Six Month Status of Early and Late Patients from the University of Toronto in the International Co-operative Study on Timing of Aneurysm Surgery

\begin{tabular}{lcr}
\hline \hline & $\begin{array}{c}\text { Early Group } \\
(\mathbf{N}=\mathbf{4 9 )}\end{array}$ & $\begin{array}{r}\text { Late Group } \\
(\mathbf{N}=\mathbf{1 4 4})\end{array}$ \\
\hline Good Recovery & $41(85.4 \%)$ & $104(72.7 \%)$ \\
Moderate Disability & $2(4.2 \%)$ & $16(11.2 \%)$ \\
Severe Disability & $1(2.1 \%)$ & $7(4.9 \%)$ \\
Vegetative Survival & $0(0 \%)$ & $4(2.8 \%)$ \\
Dead & $4(8.3 \%)$ & $12(8.4 \%)$ \\
\hline
\end{tabular}

Table 7: Incidence of Technical Problems in the Canadian, U.S. and Overall Groups of Early and Late Patients in the Three-Dose Multicentre Randomized Double-Blind Nimodipine Study

A. Intra-operative Rupture of Aneurysm:

\begin{tabular}{|c|c|c|}
\hline & Early Group & Late Group \\
\hline an Patient & $13 / 51(25 \%)$ & $1 / 4 \quad(25 \%)$ \\
\hline Patients $(\mathrm{N}=148$ & $17 / 87(20 \%)$ & $9 / 61(15 \%)$ \\
\hline Tot Doti & $30 / 138(22 \%)$ & $10 / 65(15 \%)$ \\
\hline
\end{tabular}

B. Permanent Clipping of Feeding or Perforating Arteries:

\begin{tabular}{lccc} 
B. Permanent Clipping of Feeding or Perforating Arteries: & $\begin{array}{c}\text { Larly Group } \\
\text { Late Group }\end{array}$ \\
\cline { 2 - 2 } Canadian Patients $(\mathrm{N}=55)$ & $2 / 51(4 \%)$ & & $0 / 4(0 \%)$ \\
U.S. Patients $(\mathrm{N}=148)$ & $9 / 87(10 \%)$ & & $6 / 61(10 \%)$ \\
Total Patients $(\mathrm{N}=203)$ & $11 / 138(8 \%)$ & & $6 / 65(9 \%)$ \\
\hline
\end{tabular}

consisted of predominantly early cases and the U.S. group, which was fairly evenly divided between early and late cases. There were no significant differences in the incidence of intraoperative complications between the Canadian, U.S. and overall groups, comparing early and late surgical cases (Table 7). It is noteworthy with regard to the incidence of permanent clipping of feeding or perforating arteries that an arteriogram was required in this study if a neurological deficit was to be attributed to vasospasm alone.

\section{DiSCuSSION}

These studies show a recent trend, particularly in two large Canadian centres, to earlier surgical intervention after aneurysmal subarachnoid hemorrhage. In the International Co-operative Study on Timing of Aneurysm Surgery which was conducted from January 1981 to June 1983, 25\% of the University of Toronto patients undergoing aneurysm repair were operated early $(0-3$ days post-SAH) while $75 \%$ were operated late $(\geqslant 4$ days post-SAH). Though not strictly comparable, because it included only good grade patients, the subsequent Three-Dose Multicentre Randomized Double-Blind Nimodipine Study (October 1983 - August 1984) demonstrated that most aneurysm surgery in the University of Toronto and University of Alberta was being done early. Ninety-three percent of the 
patients from these Canadian centres were operated on early, and only $7 \%$ were operated on late.

Clearly, some caution is indicated in interpreting these results, particularly as the two studies were not primarily designed to look at technical problems.

The International Co-operative Study on Timing of Aneurysm Surgery, though providing a good deal of data on operative conditions and surgical complications, based some entry data on surgeons' impressions rather than objective data such as postoperative angiograms. The Three-Dose Multicentre Randomized Double-Blind Nimodipine Study, which was designed to assess the optimal dose of Nimodipine, a calcium channel blocker previously shown to reduce severe deficits and death from vasospasm, ${ }^{9}$ had a rigorous protocol to investigate any adverse changes in a patient's course, and therefore is somewhat better suited to our present inquiry. The reported incidence of occluding feeding or perforating arteries in the Timing Study ( $2.0 \%$ of early cases and $2.7 \%$ of late cases) compared to the Three-Dose Nimodipine Study ( $8 \%$ of early cases and $9 \%$ of late cases) may therefore be due to objectivity of these data. The latter study required an arteriogram if a deficit was to be attributed to vasospasm, and this would reveal any occlusion of vessels by the clip. In the Timing Study, arteriography was not required under those circumstances.

The incidence of intra-operative rupture of the aneurysm, a potentially disastrous event, was comparable in the early and late groups in these two studies, and was similar to that in other reported series. ${ }^{10}$

While the Timing Study data for the University of Toronto cases did not indicate more difficulty achieving brain relaxation in the early surgical group, this differs from common experience and other reported series " in which the brain is found to be "tight" at early surgery. However, the protocol defined a "tight brain" as one in which adequate brain relaxation could not be achieved with the usual measures of controlled ventilation, diuretics, and cerebrospinal fluid drainage. Unfortunately our data do not permit comparison of the various measures required to slacken the brain in the early and late groups, and there may have been some differences.

\section{Conclusion}

In these two current studies of the management of aneurysmal SAH, no significant differences were shown in the incidence of technical difficulties or complications between the early surgical group (0-3 days) and the late surgical group $(\geqslant 4$ days). These data suggest that if there are differences in management morbidity and mortality between the early and late surgical groups, that these differences may be due to factors other than the ease or difficulty of surgical repair of a ruptured intracranial aneurysm at various time intervals following SAH.

\section{ACKNOWLEDGEMENTS}

The author wishes to thank Dr. Neal Kassell for permission to use data from the International Co-operative Study on Timing of Aneurysm Surgery. He would also like to thank Dr. Roy Battye of Miles Pharmaceuticals and Dr. George Allen for permission to use data from the Three-Dose Multicentre Randomized Double-Blind Nimodipine Study. The effort and co-operation of the numerous clinicians who entered and followed patients in these two studies is also gratefully acknowledged.

\section{REFERENCES}

1. Pool JL. Early treatment of ruptured intracranial aneurysms of the circle of Willis with special clip technique. Bull NY Acad Med 1959; 35: 357-369.

2. Hunt WE, Hess RM. Surgical risk as related to time of intervention in the repair of intracranial aneurysms. J Neurosurg 1968; 28: 14-19.

3. Saito I, Basugi N, Sano K. Surgical treatment of intracranial aneurysms in the acute stage, with special reference to pre- and postoperative vasospasm. Excerpta Med Int Congr Ser 1973; 293: 160.

4. Suzuki J, Yoshimoto T. Onuma T. Early operations for ruptured intracranial aneurysms - study of 31 cases operated on within four days after ruptured aneurysm. Neurol Med Chir (Tokyo) 1978; 18: 82-89.

5. Drake CG. Cerebral aneurysm surgery - an update. In: Scheinberg P, ed. Cerebrovascular Disease: Tenth Princeton Conference, New York: Raven Press, 1976; 289-310.

6. Sundt TM Jr, Whisnant JP. Subarachnoid hermorrhage from intracranial aneurysms. Surgical management and natural history of disease. New Engl J Med 1978; 299: 116-122.

7. Lougheed WM. Selection, timing and technique of aneurysm surgery of the anterior circle of Willis. Clin Neurosurg 1969; 16: 95-111.

8. Mullen S, Hanlon K, Brown F. Management of 136 consecutive supratentorial berry aneurysms. J Neurosurg 1978; 49: 794-804.

9. Allen GS, Ahn HS, Preziosi TJ, et al. Cerebral arterial spasm - a controlled trial of nimodipine in patients with subarachnoid hemorrhage. New England J Med 1983; 308: 619-624.

10. Batjer H, Samson D. Intraoperative aneurysmal rupture: Incidence, outcome, and suggestions for surgical management. Neurosurgery $1986 ; 18: 701-707$.

11. Auer LM. Acute operation and preventive nimodipine improve outcome in patients with ruptured cerebral aneurysms. Neurosurgery 1984; 15: 57-66. 